\title{
Vida de Galileo, de Bertolt Brecht: el campo científico de una época y el papel del intelectual en tiempos de crisis*
}

\author{
[Versión en Castellano] \\ Life of Galileo, by Bertolt Brecht: the Scientific Field of an Era \\ and the Role of the Intellectual in Times of Crisis \\ Vida de Galileu, de Bertolt Brecht: o campo científico de uma época \\ e o papel do intelectual em tempos de crise
}

Recibido el 11 de diciembre, 2019. Aceptado el 7 de mayo, 2020.

\author{
Daniel Clavijo-Tavera** \\ https://orcid.org/0000-0003-4266-3681 \\ Colombia
}

Para citar este artículo:

Clavijo-Tavera, Daniel (2020).

Vida de Galileo, de Bertolt Brecht: el campo científico de una época y el papel del intelectual en tiempos de crisis.

Ánfora, 27(49), 43-66.

https://doi.org/10.30854/anfv27.n49.2020.735

Universidad Autónoma de

Manizales. ISSN 0121-6538/

e-ISSN 2248-6941.

CC BY-NC-SA 4.0

\section{Resumen}

Objetivo: con base en el texto Vida de Galileo, de Bertolt Brecht, y a partir de la teoría de los campos sociales de Pierre Bourdieu, el artículo se propone evidenciar el diálogo entre la obra y la toma de posición política y estética- de Brecht en relación con el papel del intelectual en tiempos de crisis, así como una reflexión en torno a la retractación del héroe, desde la perspectiva de la necesidad histórica y de las condiciones sociales de producción y de recepción de la obra. Metodología: el estudio se vale de la metodología del análisis social de Pierre Bourdieu y de nociones como espacio social,

\footnotetext{
* Artículo derivado de la Investigación titulada "Vida de Galileo, de Bertolt Brecht: el campo científico de una época y el papel del intelectual en tiempos de crisis ". La financiación del proyecto fue asumida por el investigador, quien declara que no hubo conflicto de intereses en la ejecución del proyecto de investigación.

** Comunicador social y periodista. Candidato a doctor en Humanidades de la Universidad EAFIT, Medellín, Colombia. Adscrito al grupo de investigación Estudios en filosofía, hermenéutica y narrativas, del Departamento de Humanidades de la Universidad EAFIT. Correo electrónico: oclavijo@eafit.edu.co
} 
campos sociales, autonomía, heteronomía y habitus, para establecer tanto las relaciones entre los campos científico, económico y del poder en la obra como el diálogo con la toma de posición brechtiana a mediados del siglo XX. Resultados: el análisis social de Pierre Bourdieu permite evidenciar el complejo entramado de tensiones, redes y temporalidades sobre el que se construye Vida de Galileo y posibilita la apertura para el diálogo entre las redes de relaciones y las estructuras sociales que se configura entre el discurso ficcional y las condiciones de producción y recepción de la obra. Conclusiones: se da cuenta de la relevancia del análisis social como método que, con énfasis en la experiencia práctica, se aleja de la visión esencialista de la obra literaria; las potencialidades del análisis se presentan en la relación de los dos momentos del análisis: de un lado, en el marco de la obra; de otro, en la toma de posición del autor frente a la influencia de los totalitarismos de mediados del siglo XX.

Palabras-clave: Pierre Bourdieu; Campos sociales; Campo literario; Bertolt Brecht; Vida de Galileo.

\section{Abstract}

Objective: based on the text Life of Galileo, by Bertolt Brecht, and the theory of the social fields of Pierre Bourdieu, the article sets out to demonstrate the dialogue between the work and the taking of positions - politically and aesthetically - by Brecht in relation to the role of the intellectual in times of crisis, as well as a reflection on the retraction of the hero, from the perspective of historical need and the social conditions of production and reception of the work. Methodology: the study uses the methodology of Pierre Bourdieu's social analysis and notions such as social space, social fields, autonomy, heteronomy and habitus, to establish both the relations between the scientific, economic and power fields in the work and the dialogue with the taking of the Brechtian position in the middle of the 20th century. Results: Pierre Bourdieu's social analysis reveals the complex network of tensions, networks and temporalities on which Life of Galileo is built and enables the opening of dialogue between the networks of relationships and the social structures that are configured between fictional discourse and the conditions of production and reception of the work. Conclusions: it realizes the relevance of social analysis as a method that, with emphasis on practical experience, departs from the essentialist vision of literary work; the potentialities of the analysis are presented in the relationship of the two moments of the analysis: on the one hand, within the framework of Life of Galileo; on the other hand, in taking the author's position against the influence of totalitarianism in the mid-20th century. 
Keywords: Pierre Bourdieu; Social fields; Literary Field; Bertolt Brecht; Life of Galileo

\section{Resumo}

Objetivo: com base no texto Vida de Galileu, de Bertolt Brecht, e com base na teoria dos campos sociais de Pierre Bourdieu, o artigo propõe demonstrar o diálogo entre o trabalho e a tomada de posições - política e estética - de Brecht em relação ao papel do intelectual em tempos de crise, bem como uma reflexão sobre a retração do herói, na perspectiva da necessidade histórica e das condições sociais de produção e recepção da obra. Metodologia: o estudo utiliza a metodologia da análise social de Pierre Bourdieu e noções como espaço social, campos sociais, autonomia, heteronomia e habitus, para estabelecer as relações entre os campos científico, econômico e de poder na obra como diálogo com a posição brechtiana em meados do século XX. Resultados: a análise social de Pierre Bourdieu revela a complexa rede de tensões, redes e temporalidades nas quais é construída a Vida de Galileu e permite uma abertura para o diálogo entre as redes de relacionamentos e as estruturas sociais configuradas entre o discurso ficcional e as condições de produção e recepção da obra. Conclusões: percebe a relevância da análise social como um método que, com ênfase na experiência prática, se afasta da visão essencialista da obra literária; as potencialidades da análise são apresentadas na relação dos dois momentos da análise: por um lado, no âmbito do trabalho; por outro, ao assumir a posição do autor contra a influência do totalitarismo em meados do século XX.

Palavras-chave: Pierre Bourdieu; Campos sociais; Campo literário; Bertolt Brecht; Vida de Galileu 


\section{Introducción}

Con el objeto de poner en práctica su propuesta metodológica de un análisis sociológico e histórico de un texto literario, Pierre Bourdieu inicia su ensayo Las reglas del arte. Génesis y estructuras del campo literario (2015) con un estudio sobre La educación sentimental, de Gustave Flaubert, novela de la que afirma: "proporciona todos los instrumentos necesarios para su propio análisis sociológico" (Bourdieu, 2015, p. 19). Para llevar a cabo su aproximación, Bourdieu se adentra en la descripción de los campos sociales que entran en juego en la novela -polo del arte y la política y polo de la política y los negocios-, las tensiones y la forma en que el héroe-Frédéric- se desenvuelve en ellos, y anota que la estructura del espacio social en que se desarrollan las aventuras de Frédéric es también la estructura del espacio social en que se sitúa el autor, lectura que otros estudiosos habían pasado por alto:

La educación sentimental restituye de forma extraordinariamente exacta la estructura del mundo social en el que ha sido elaborada e incluso las estructuras mentales que, moldeadas por estas estructuras sociales, constituyen el principio generador de la obra en la que estas estructuras se revelan. Pero lo hace con los medios que le son propios, es decir ver y sentir, con ejemplificaciones o, mejor aún, evocaciones, en el sentido fuerte de hechizos capaces de producir unos efectos, particularmente sobre los cuerpos, mediante la "magia evocadora" de palabras aptas para "hablar a la sensibilidad" y para conseguir una creencia y una participación imaginaria análogas a las que atribuimos habitualmente al mundo real (Bourdieu, 2015, p. 63).

La búsqueda de Bourdieu pretende tomar distancia de la visión esencialista que tradicionalmente dominó la historia estética de occidente e intenta implantar un modelo de aproximación a la experiencia estética consciente de la historicidad y la práctica, capaz de dar cuenta de las condiciones sociales de producción y recepción de la obra de arte, en relación con el espacio social y los campos -del poder, literario, artístico, etc.- en los que esta interactúa ${ }^{1}$.

En línea con el análisis emprendido por Bourdieu sobre el texto de Flaubert, Vida de Galileo, de Bertolt Brecht (2009), se constituye también en un complejo encuentro de planos, tensiones y temporalidades que se valoriza -se "intensifica" (Bourdieu, 2015, p. 13)- con las potencialidades que permite el análisis de la

\footnotetext{
1. Tomando distancia de la vaga noción de contexto, Bourdieu entiende el campo como una "red de relaciones objetivas entre posiciones objetivamente definidas por su situación (situs) actual y potencial en la estructura de la distribución de las especies de capital (o de poder) cuya posesión impone la obtención de los beneficios específicos puestos en juego en el campo, y, a la vez, por su relación objetiva con las otras posiciones (dominación o subordinación, etc.)" (Bourdieu, 1989, pp. 3-4).
} 
crítica social. Tanto las luchas internas -configuradas a partir de la fábula, de las trayectorias y de las tomas de posición de los personajes-como las particulares condiciones de producción y de lectura del texto y el estatus del autor como teórico en el campo artístico y participante activo en el campo político permiten una aproximación a la red de relaciones -e interacciones entre el campo literario y el espacio social- en la que se teje la obra para ofrecer esa perspectiva "menos sobrehumana" (Bourdieu, 2015, p. 15) con la que el propio Bourdieu justificó su propuesta teórico-metodológica. En el caso de Bertolt Brecht, el análisis de los campos sociales resulta aún más pertinente, si se tiene en cuenta que el propio Brecht persiguió siempre un teatro basado "menos en el individuo y más en la colectividad, menos en el 'destino' y más en las coordenadas sociales” (Dieterich, 2015, p. 12).

Cabe mencionar que el alcance de la consonancia obra-autor no consiste en identificar posibles datos autobiográficos del escritor en la trayectoria del héroe, como lo aclara Bourdieu en su estudio de La educación sentimental, sino en emprender la objetivación del propio ser, de autoanálisis, de socioanálisis (2015, pp. 52-53). No se busca entonces la verificación de hechos históricamente constatables con pasajes de la fábula sino de construir redes de relaciones y estructuras sociales entre el discurso ficcional y las condiciones históricas de producción/ recepción de la obra:

No hay mejor prueba de todo lo que separa la escritura literaria de la escritura científica que esta capacidad, que le pertenece por derecho propio, de concentrar y condensar en la singularidad concreta de una figura sensible y de una aventura individual, que funciona a la vez como metáfora y como metonimia, toda la complejidad de una estructura y de una historia que el análisis científico tiene que desarrollar y extender muy laboriosamente (Bourdieu, 2015, p. 51).

\section{Metodología}

Metodológicamente, esta Reflexión parte del análisis del texto Vida de Galileo, desde la perspectiva de las relaciones que se revelan entre el héroe y los campos científico, económico y de poder. Posteriormente, analiza pasajes del pensamiento brechtiano en los que se evidencia la preocupación del autor por el papel del intelectual en tiempos de crisis y las resonancias de dicha posición en la "aventura individual" del Galileo literario. Frente a la aparición de la bomba atómica en momentos en que Brecht reescribía la obra, la recreación ficcional del científico -y, en particular, su retractación- puede leerse en sintonía con la toma 
de posición (Bourdieu, 1989, p. 5) -política y estética- del autor en el espacio social en el que se produjo y en el que fue recibido el texto².

\section{Resultados}

\section{El espacio social de Vida de Galileo}

Vida de Galileo ficcionaliza los últimos 30 años de la vida del matemático y físico italiano, específicamente en la tensión entre los hallazgos de su práctica científica $^{3}$ y el poder de la iglesia católica; en particular, durante los tiempos de prohibiciones y represión de la Inquisición en el siglo XVII. Las primeras escenas de la obra ofrecen ya un amplio panorama de las complejas y ambiguas relaciones en las que se enmarcan las condiciones sociales y el quehacer del héroe -que podría entenderse como el campo de la investigación científica ${ }^{4}$ - y campos como el del poder económico y el del poder político, representado tanto por las familias cortesanas de Venecia y Florencia -el Dogo y los Médicis, respectivamente-, como por miembros del clero en Florencia y Roma, institución que, según lo aclaró el propio Brecht, es representada desde su posición de autoridad mas no desde su espiritualidad (Brecht, 2015, p. 322).

Como personaje mutable y contradictorio, Galileo gravita y toma posiciones diversas entre los campos, al vaivén de intereses, necesidades y circunstancias específicas; en este sentido, interactúa de manera indiferente con personajes

\footnotetext{
2. Dentro del campo, Bourdieu tiene en cuenta la idea de "campo de las posiciones" como las propiedades de los ocupantes y la idea de "campo de las tomas de posición" como las prácticas de los agentes sociales comprometidos en el campo: "obras literarias o artísticas, evidentemente, pero también hay actos y discursos políticos, manifiestos o polémicas, etc." (Bourdieu, 1989, p. 4).

3. En el capítulo titulado "Galileo y la cultura de su época", Eugenio Garin señala que es precisamente durante los años 1609 y 1610 cuando el trabajo de Galileo sufre un cambio de orientación: hasta ese entonces se había concentrado en los problemas del movimiento; a partir de 1609, con la construcción del telescopio, el descubrimiento de los satélites de Júpiter, las observaciones sobre los cuerpos de Saturno y las manchas solares, entre otras, las investigaciones se centran en la cosmología (1984, p. 340).

4. De acuerdo con Garin, la ampliación cultural que tuvo lugar en el renacimiento, en la que se enmarcan las investigaciones científicas de Galileo, se dio al margen de la universidad, "o bien en zonas y disciplinas marginales y de importancia secundaria [...] entre los siglos XV y XVI la nueva cultura no tiene su punto de partida en la universidad ni triunfa en tal marco institucional: cuando penetra en la universidad lo hace, por decirlo de algún modo, en terrenos fronterizos. Claustros y cancillerías, cortes y 'academias', es decir, asambleas de gentes doctas libremente constituidas, se conforman como los centros desde donde se irradia el nuevo saber" (1984, p. 319).
} 
de trayectorias sociales tan distantes como las que existen entre artesanos o fabricantes de instrumentos del Gran Arsenal de Venecia y personalidades como el Gran Duque de Médicis y el Papa Urbano VIII, entre otros.

De acuerdo con la primera didascalia de la obra, Galileo trabaja en un gabinete de estudio pobre. Vive con su hija Virginia, su ama de llaves -la señora Sarti- y Andrea, el hijo de esta última, un joven de 11 años de edad que se presenta como el principal discípulo del científico. Mientras las horas de Galileo se van en las investigaciones didácticas que pone en práctica con Andrea, la señora Sarti le recuerda permanentemente al matemático que tiene deudas por las cuales debe responder; particularmente, con el lechero, quien, como lo hacen los astros alrededor de la Tierra, "pronto empezará a dar vueltas alrededor de nuestra casa" (Brecht, 2009, p. 9).

En cuanto a la independencia económica, Galileo no es un hombre "libre". Debe destinar buena parte de su tiempo a dictar clases particulares, actividad que le impide dedicarse como quisiera a sus investigaciones. Su posición dependiente es presentada en esta primera parte del texto por medio de su interacción con un hombre rico, Ludovico Marsili, por un lado, y con un símbolo del campo cultural y de la investigación científica, representado por la academia -señor Priuli, Secretario de la Universidad 5 -, por el otro, espacio social que, a su vez, carece de autonomía frente al capital económico.

Durante este pasaje de la primera escena, Galileo se encuentra explicándole a Andrea, con la ayuda de una manzana, cómo es que la Tierra gira alrededor del sol y por qué razón no es posible percibir su movimiento, cuando es interrumpido por la señora Sarti, quien le anuncia que ha llegado un hombre con una carta de recomendación para tomar clases particulares con él. Es Ludovico Marsili, quien no tiene interés alguno en el conocimiento de las ciencias sino que busca valerse de ellas como una especie de lubricante social: "Ludovico: Mi madre opina que un poco de ciencia es necesaria. Todo el mundo bebe hoy su vino con ciencia, ¿no?” (Brecht, 2009, p. 18). Sin importar el grado de interés que este pueda tener en el aprendizaje, Galileo se ve en la necesidad de tomar el encargo, en sacrificio de Andrea, quien evidentemente sí está interesado en las investigaciones y quien, así como ya comprendió aquel fenómeno físico de la gravedad, debe ahora comprender los mecanismos que rigen el conocimiento: el saber no

\footnotetext{
5. Como se menciona en una nota anterior, es necesario tener en cuenta que el campo de la investigación científica o de la "nueva cultura" - para decirlo en términos de Garin- no se configura únicamente a partir de la institución universitaria sino que se ubica en "la dialéctica entre universidad y cultura no universitaria" (Garin, 1984, p. 324). Dicha tensión se hace evidente en la obra de Brecht en el entramado de relaciones diversas en que se desenvuelve Galileo, entre autoridades académicas, clases particulares, investigaciones independientes, etc.
} 
es de quien lo persigue de manera romántica y consagrada sino de quien cuente con los medios para acceder a él.

LUDOVICO: Y como mi madre deseaba que viera un poco lo que pasaba en las ciencias...

GALILEO: Lecciones privadas: diez escudos al mes

LUDOVICO: Muy bien, señor

GALILEO: ¿Qué le interesa?

LUDOVICO: Los caballos

GALILEO: Ajá.

LUDOVICO: Yo no tengo cabeza para las ciencias, señor Galilei.

GALILEO: Ajá. En ese caso, serán quince escudos

LUDOVICO: Muy bien, señor Galilei

GALILEO: Tendré que darle clase muy temprano. El perjudicado serás tú, Andrea. Naturalmente, tendré que prescindir de ti. Lo comprendes, ¿no? Tú no pagas nada.

ANDREA: Ya me voy. ¿Puedo llevarme la manzana?

GALILEO: Sí (Brecht, 2009, p. 17).

En este sentido, el encuentro con la institucionalidad académica es aún más revelador. Una vez termina la cita con Ludovico Marsili, la señora Sarti le anuncia a su amo que el Secretario de la Universidad, señor Priuli, busca a Galileo, quien manifiesta que este -el Secretario- es “persona importante”, pues podría representarle 500 escudos adicionales que había solicitado a la academia por sus investigaciones, dinero que podría llevarlo a prescindir de las clases particulares. Sin embargo, las noticias no son las que espera:

EL SECRETARIO: Vengo para tratar de su solicitud de que se le suba el sueldo a 1,000 escudos. Por desgracia, no puedo apoyarla en la Universidad. Usted sabe que los cursos de matemáticas no traen alumnos a la universidad. Por decirlo así, las Matemáticas son un arte poco lucrativa. Y no porque la República no las estime sobremanera. No son tan necesarias como la Filosofía ni tan útiles como la Teología, pero ¡dan a quien las conoce infinitas satisfacciones! (Brecht, 2009, pp. 18-19).

El campo de la ciencia y el conocimiento -en este caso, representado por las matemáticas, la física, la filosofía o la teología, donde las primeras se encuentran 
en una posición desfavorable frente a las segundas ${ }^{6}$ - obedece entonces a las dinámicas del mercado; es decir, responde a una posición dominada frente al poder económico.

Pierre Bourdieu describe este comportamiento por medio de la relación entre el campo artístico y los campos del poder, y establece las nociones de autonomía y heteronomía. En la interacción entre campos sociales ningún campo es enteramente independiente; el campo cultural se inscribe dentro del campo del poder, espacio de tensión permanente, donde entran en juego conceptos como capital económico o capital político. Si, en determinado caso, se imponen principios económicos y políticos en el campo cultural, se presenta a una jerarquización heterónoma; si, por el contrario, el campo cultural logra liberarse de las leyes del mercado, se presenta una jerarquización autónoma (Bourdieu, 1989, p. 15). En la obra, tanto las prácticas de Galileo -en un mayor grado- como las decisiones del aparato educativo se acercan a una jerarquización heterónoma frente a los centros económicos.

La extensa conversación entre Galileo y el señor Priuli devela también otro fenómeno que subyace a esta tensión entre las relaciones ciencia-academia-poder y es la aparente libertad que el campo del poder le otorga al campo cultural, beneficio que para Galileo no es más que una estrategia de control, a través de una ilusión de autonomía, sobre las dinámicas de las prácticas y los desarrollos científicos:

GALILEO: Señor, ¡tengo demasiados [alumnos]! No hago más que enseñar y ¿cuándo voy a aprender yo? Hombre de Dios, yo no soy tan sabelotodo como los señores de la Facultad de Filosofía. Soy tonto. No entiendo de nada. Por eso me veo obligado a rellenar las lagunas de mis conocimientos. ¿Y cuándo voy a hacerlo? ¿Cuándo voy a investigar? [...] ¿Y cómo puedo avanzar si, para poder vivir, tengo que meter en la cabeza a todo imbécil que pueda pagarlo eso de que dos líneas paralelas se cortan en el infinito?

EL SECRETARIO: No olvide que la República quizá no pague tanto como algunos príncipes, pero en cambio garantiza la libertad de investigación $[\ldots]$

6. A manera de dato anecdótico, Eugenio Garin (1984) señala que Galileo era consciente de esta relación asimétrica en el reconocimiento de las ciencias, por lo que en algún momento solicitó el título de filósofo. Para 1589 el sueldo de un profesor de matemáticas era de 60 florines; para 1592 era de 180 florines y para 1609 ya era de 1000 florines. 
GALILEO: [ $\quad \ldots]$ Vuestra protección de la libertad de pensamiento es buen negocio, ¿no? Al recordar que en otras partes reina y quema la Inquisición, obtenéis profesores buenos y baratos. Os resarcís de la protección que ofrecéis contra la Inquisición pagando los sueldos más bajos (Brecht, 2009, pp. 19-20).

Pero la toma de posición crítica por parte de Galileo no se da únicamente en relación con los otros campos. Desde la escena inicial en que ilustra a Andrea sobre sus hallazgos, declara su postura como agente del campo mismo de la ciencia y cómo su investigación -que continúa la línea de Copérnico y Giordano Bruno- toma distancia del tradicional sistema ptolemaico, tan "bonito" pero tan “inmóvil", cuyo pilar era la idea de que los astros giraban alrededor de la Tierra. El mundo ha entrado en una nueva era -filosófica, si se quiere ${ }^{7}$, el tiempo de la movilidad, de la inestabilidad, del quiebre de las grandes certezas y del posicionamiento de la duda como mirada crítica:

GALILEO: [...] Porque donde durante mil años reinó la fe, precisamente allí reina la duda. Todo el mundo dice: sí, eso está en los libros, pero vamos a verlo por nosotros mismos. A las verdades más celebradas se les dan palmaditas en la espalda; aquello de lo que nunca se dudó hoy se pone en duda [...]

GALILEO: [...] Y la Tierra gira alegremente alrededor del Sol, y las pescaderas, mercaderes, príncipes y cardenales, y hasta el Papa, giran con ella. El Universo, sin embargo, ha perdido en una noche su centro, y a la mañana siguiente tenía innumerables centros. De forma que ahora todos y ninguno parecen ese centro, porque de pronto hay mucho sitio (Brecht, 2009, pp. 12-13).

No solo se tambalean las verdades eternas sino que se abren múltiples centros: se rompe la visión hegemónica para dar cabida a nuevas versiones. La toma de posición de Galileo frente al campo de la ciencia en el siglo XVII es en reali-

\footnotetext{
7. De acuerdo con Garin, la perspectiva copernicana implicó una nueva visión de las cosas y de ahí que se le conciba como derivada de una nueva perspectiva filosófica: "Ella, y solo ella, permite la radical transformación de los cuadros generales del saber vinculada a la revolución astronómica. No es pues casual que a lo largo de casi dos siglos filósofos y científicos parecen tomar el relevo unos de otros: de Copérnico se pasa a Bruno, de Bruno a Galileo. Del mismo modo que la obra de Bruno sería incomprensible sin Copérnico, sin Bruno -y bien se ocupa Kepler de señalarlo- difícilmente podríamos concebir ciertas perspectivas generales de la ciencia del siglo XVII" (Garin, 1984, p. 274).
} 
dad la manifestación brechtiana frente a la conciencia de la historia -política y estética- en la Europa del siglo XX -relación que será abordada más adelante-. Los soportes conceptuales, posicionados por los encargados de contar y mantener la historia, han entrado en crisis y es momento de escuchar nuevas voces; voces que no solo aparecen ahora como parte del registro, sino que son las que marcan el rompimiento.

Ya en su análisis sobre la poesía brechtiana, Hannah Arendt señalaba que más allá de la causa de la justicia social o de su aproximación a la historia desde la perspectiva del materialismo dialéctico, el motivo más profundo que tenía Brecht para romper con la tradición era la rabia ante el rumbo que había tomado el mundo y frente al hecho de que fueran los vencedores los que decidieran qué debía registrar y recordar la humanidad: "Brecht no escribe su poesía solo para los desfavorecidos, sino para aquellos hombres, vivos o muertos, cuya voz no ha sido nunca escuchada” (Arendt, 2014, p. 132). En Vida de Galileo, Galileo explicita así el cambio de perspectiva:

GALILEO: $[\ldots]$ En Siena, de joven, vi cómo algunos trabajadores
de la construcción sustituían una forma milenaria
de mover los bloques de granito por una colocación
nueva y más racional de las sogas, tras discutir cinco
minutos. Allí y entonces lo supe: la época antigua
había acabado y comenzaba una nueva. Pronto sabrá la
Humanidad qué ocurre con su vivienda, con el cuerpo
celeste en que habita. Lo que dicen los libros antiguos
no le basta (Brecht, 2009, p. 12).

El campo del poder político, como se mencionó anteriormente, aparece representado por diversas instancias a lo largo de la obra, buena parte de ellas relacionada con las ciudades y el tipo de gobierno de cada una. Al inicio, en la República de Venecia, se encuentra el Dogo, quien es engañado por Galileo, cuando cree que el matemático ha creado el telescopio y que dicho invento representará importantes beneficios comerciales para su corte. Se organiza entonces un evento en que Galileo le regala a la ciudad el más reciente producto de su genialidad: un tubo con lentes a los costados que permite ver de cerca objetos que se encuentran a una distancia considerable.

El matemático afirma que le tomó más de 17 años desarrollar el artefacto, cuando en realidad lo había copiado un par de días atrás de un modelo holandés del que le había hablado Ludovico Marsili en la entrevista. Durante la ceremonia, en una muestra de desencanto, dice Ludovico: "Y yo creo que empiezo a comprender algo de la Ciencia”. La frase simboliza la desmitificación del «genio 
creador», al evidenciar que lo que Galileo ha logrado es un gran gesto como relacionista público en el campo del poder para conservar su posición privilegiada; en otras palabras, una hábil maniobra para mantener su capital simbólico.

La incómoda situación económica de Galileo en los alrededores de Venecia -el poco tiempo con el que cuenta para llevar a cabo sus investigaciones- lo obliga a valerse de ese mismo relacionamiento, de sus contactos políticos en la Toscana, hecho que revela a un Galileo muy cercano a Cosme de Médicis, Gran Duque de Florencia, a quien le escribe para solicitarle que lo reciba como matemático en su corte, con el fin de obtener "itiempo, tiempo, tiempo, tiempo!" para continuar con sus indagaciones, que, ahora, gracias al telescopio, se centran en los cuerpos celestes.

En la carta que le envía al Duque de Florencia, en un tono servil y sumiso reconocido por el propio autor de la misiva-, Galileo le revela que ha descubierto unos astros a los que piensa llamar "Estrellas Mediceas": "Al dar a las estrellas que he descubierto el egregio nombre de la Casa de los Médicis, soy consciente de que la elevación al cielo estrellado de dioses y héroes los ha glorificado, pero en este caso, por el contrario, será el egregio nombre de los Médicis el que daría a esas estrellas memoria imperecedera" (Brecht, 2009, pp. 39-40).

El tono de la carta evoca aquellas palabras saturadas de elogio - esta vez históricas- que Giorgio Vasari dedicara también al mismo Cosme de Médicis al inicio de sus biografías de artistas de su época ${ }^{8}$. Elogios de este tipo eran frecuentes durante el Renacimiento y podrían asumirse como poco desinteresados pues, al exaltar la vida de algún poderoso para la posteridad, se garantizaba la posteridad del propio elogiador. En la carta del Galileo de Brecht es perceptible, además, un claro interés práctico; Galileo nombra las estrellas con el nombre del gobernante porque necesita cambiar de trabajo, un hecho cuyo efectismo es reconocido hasta por la poco perspicaz Virginia: "Claro que te aceptarán, padre, con las nuevas estrellas y todo eso" (Brecht, 2009, p. 38).

Si bien la posición de Galileo en el campo del poder toscano es privilegiada -cabe aclarar que el Duque tiene nueve años de edad-, sus planteamientos en el campo científico florentino son objeto de mucha resistencia por parte de los guardianes de la tradición: algunos monjes, un matemático y un filósofo, defensores de la astronomía aristotélica se oponen radicalmente a Galileo, en un obstinado arraigo a sus creencias, al punto de que ni siquiera se atreven a mirar por el telescopio lo que el físico les quiere mostrar: "El matemático: Se sentiría la tentación de responder que su anteojo, al mostrar lo que no puede ser, no es muy de fiar ¿no?” (Brecht, 2009, p. 46). En esta escena, donde el discurso calla la

8. "Al ilustrísimo y excelentísimo señor Cosme de Médicis, Duque de Florencia y Siena", en Las vidas de los más excelentes pintores, escultores y arquitectos, escritas por Giorgio Vasari (Vasari, 1996, p. 25). 
experimentación, Brecht representa aquello que Bertrand Russell (1975) calificó como el conflicto entre el espíritu de inducción y el espíritu de deducción, más que una simple diferencia entre el libre pensamiento o el fanatismo o entre la ciencia y la religión?. Resignado, Galileo responde: "La verdad es hija del tiempo y no de la autoridad" (Brecht, 2009, p. 49). Hoy, bajo el lente de Bourdieu y el enfoque de los campos sociales, podría contestársele al matemático que el tiempo es hijo de la autoridad.

El otro centro de poder con el que se relaciona Galileo es el de los máximos jefes de la Iglesia Católica en Roma, donde se encuentran, entre otros, el Cardenal Barberini -próximo Papa Urbano VIII-, el Cardenal Bellarmino y el Cardenal Inquisidor. La posición del héroe en este espacio es inestable y dependiente de quien esté encargado de tomar las decisiones.

La situación inicial en el Colegio Romano, instituto de investigaciones del Vaticano, es de desprestigio, pues mientras Clavius, el gran astrónomo, evalúa los trabajos de Galileo, los miembros de la Iglesia se burlan de sus tesis: "UN MONJE, haciendo el payaso: Me da vértigo. La Tierra da vueltas demasiado aprisa. Permítame que me agarre a usted, profesor. Finge tambalearse y se agarra a un sabio" (Brecht, 2009, p. 58). Una vez Clavius -campo de la ciencia que trabaja para el campo del poder- le da la razón a Galileo, el héroe obtendrá el reconocimiento, los elogios y el mayor capital simbólico que alcanzará en toda la obra en relación con el poder. Incluso, el Cardenal Bellarmino ofrece en su casa un baile en honor a Galileo, a la vez que su fama se extiende por la región: "Virginia: Padre, el peluquero de Via del Trionfo me hizo pasar la primera y dejó esperando a cuatro señoras. Reconoció enseguida tu nombre” (Brecht, 2009, p. 64).

La tensión dramática emerge de nuevo con una reconfiguración del campo del poder en torno al trabajo de Galileo: la Santa Inquisición ha decidido que la teoría de Copérnico, según la cual el Sol es el centro del universo y permanece quieto, y la Tierra no es el centro del universo y se mueve, es "demencial, absurda y herética” y obliga a Galileo a renunciar a ella; está autorizado a abordarla únicamente como hipótesis matemática.

El campo de la ciencia, frente a la Iglesia, es claramente heterónomo: "BELLARMINo: La Ciencia es hija legítima y muy amada de la Iglesia, señor Galilei” (Brecht, 2009, p. 69). El avance del conocimiento del héroe no puede darse sin el beneplácito del clero, institución que, a su vez, también ha necesitado de la

\footnotetext{
9. De hecho, afirma Russell que "[I]os que creen en la deducción como método para llegar al conocimiento se ven obligados a tomar sus premisas de alguna parte, generalmente de un libro sagrado. La deducción procedente de libros inspirados es el método de llegar a la verdad empleado por los juristas, cristianos, mahometanos y comunistas. Y puesto que la deducción, como medio de alcanzar el conocimiento, fracasa cuando existe duda sobre las premisas, los que creen en la deducción tienen que ser enemigos de los que discuten la autoridad de los libros sagrados" (1975, p. 28).
} 
ciencia, pues las Sagradas Escrituras han logrado mantenerse como versión hegemónica gracias al soporte que han encontrado en la tradición de la astronomía aristotélica. La relación, si bien marca un dominante y un dominado, con una clara posición favorable para la Iglesia, es de interdependencia.

Durante ocho años, Galileo es obligado a abandonar sus investigaciones hasta que el Cardenal Barberini, amigo de la ciencia, es nombrado Papa y Galileo reanuda sus trabajos. Sin embargo, tiempo después, la Santa Inquisición manifiesta su intención de interrogar a Galileo en Roma. La posición del poder de turno es presentada en una conversación íntima entre el Papa y el Inquisidor, donde se muestra la posición ambivalente de Galileo para la Iglesia: sus teorías son peligrosas, pero comercialmente representa beneficios; además, cuenta con una buena posición frente a otros agentes estratégicos; tampoco se desconoce su importancia para la ciencia. En ese momento, se decide que no será ejecutado pero que será presionado para que se retracte:

EL INQUISIDOR: Incita a los unos y corrompe a los otros. Las ciudades marítimas del norte de Italia exigen cada vez con más insistencia para sus barcos las cartas astronómicas del señor Galilei. Y tendremos que transigir, porque se trata de intereses materiales.

EL PAPA: Pero esas cartas astronómicas se basan en sus afirmaciones heréticas. Precisamente en movimientos de ciertos astros que no podrían producirse si se rechaza su teoría. No se puede condenar la teoría y aceptar las cartas astronómicas.

EL INQUISIDOR: ¿Por qué no? [ ...]

EL PAPA: $\quad[\ldots] \mathrm{Al}$ fin y al cabo, ese hombre es el mayor físico de esta época, la luz de Italia, y no es un iluso cualquiera. Tiene amigos. Ahí está Versalles. Ahí está la Corte de Viena. Calificarán a la Santa Sede de sumidero de prejuicios podridos. ¡No hay que tocarlo! (Brecht, 2009, p. 105).

Y llega la retractación. Como si se tratara de una muerte en el escenario bajo las disposiciones del teatro griego, el momento no se presenta explícitamente, sino que el lector se entera de él por el sonido de las campanas de San Marcos que escuchan los discípulos y familiares de Galileo y que anuncian que no ha habido ejecución. La decepción es absoluta -excepto Virginia, católica, quien se alegra-: el gran matemático ha traicionado a su propia ciencia. Andrea, el más cercano de sus seguidores, no podrá perdonarlo: "ANDREA, en voz alta: 
¡Pobre del país que no tiene héroes! [ ...] GALILEO: No. Pobre del país que necesita héroes" (Brecht, 2009, p. 112).

\section{La retractación de Galileo y la toma de posición de Bertolt Brecht}

La retractación de Galileo en Vida de Galileo ha sido uno de los problemas más abordados por los estudiosos de la obra de Brecht. El propio dramaturgo dedica varios de sus comentarios a esta acción, a la que denomina "el pecado original de las ciencias naturales modernas":

Constituiría una gran debilidad de la obra si tuvieran razón los físicos, que me decían con aprobación que la retractación de Galileo estaba explicada, a pesar de algunas «vacilaciones», como razonable, argumentando que esa retractación le había permitido al sabio continuar sus investigaciones científicas y entregarlas a la posteridad. Galileo enriqueció la astronomía y la física, y al mismo tiempo despojó a estas ciencias de su significado social. Con su crítica a la Biblia y a la Iglesia, la astronomía y la física estuvieron durante un tiempo en la barricada de cualquier progreso. Es cierto que, a pesar de todo, se produjo un cambio en los siglos siguientes, y la astronomía y la física contribuyeron a él, pero lo que se produjo fue un cambio y no una revolución, el escándalo degeneró en una disputa entre especialistas. La Iglesia, y con ella la reacción al completo, pudo retirarse ordenadamente y conservar más o menos su poder. Y esas ciencias mismas nunca más volvieron a ocupar aquella gran posición en la sociedad, nunca más volvieron a estar tan cerca del pueblo [...] La bomba atómica es, como fenómeno técnico y social, el clásico producto final del genio científico y del fracaso social de Galileo (Brecht, 2015, p. 319).

La relación ciencia y sentido social -o ética y política (Suvin, 1998)- de la que habla Brecht es presentada de manera muy explícita en la octava escena de la obra -antes de la retractación que ocurrirá en la escena 13-, por medio de la larga conversación que sostiene Galileo con un pequeño monje, inquieto también por las cuestiones científicas y a quien le constan sus «verdades»; alguien que ha decidido abandonar la astronomía por los peligros que para la humanidad puede representar una investigación sin freno.

El verdadero problema, afirma el monje, no son las torturas que pueda recibir quien defienda cierta postura científica sino el hecho de que los campesinos no están preparados para las nuevas teorías: "EL PEQUEÑO MONJE, muy agitado: ¡Son los motivos más altos los que nos deben hacer callar, es la paz de las almas de los desheredados! [ …] ¿Y no cree que la verdad, cuando es la verdad, se impone 
también sin nosotros?” (Brecht, 2009, pp. 76-78). Y, si bien Galileo coincide con el monje en que el desarrollo científico no se trata de los planetas sino "de los campesinos de la Campania”, precisamente, por eso, no está dispuesto a callar:

GALILEO: No, no, no. Solo se impone tanta verdad como nosotros imponemos; la victoria de la Razón solo puede ser la victoria de los que razonan. ¡Describís a vuestros campesinos de la Campania como si fueran el musgo que cubre sus chozas! ¡Cómo puede suponer nadie que la suma de los ángulos de un triángulo pueda contradecir sus necesidades! Pero si no se movilizan y aprenden a pensar, ni los más hermosos sistemas de riego les servirán de nada. Diablos, yo veo la divina paciencia de esas gentes, pero ¿dónde está su divina cólera? (Brecht, 2009, p. 78).

De la contradicción del héroe a las palabras que había pronunciado escenas antes frente al monje se desprende la idea de la traición, entendida como un gesto contra el pueblo, contra la ciencia y contra la responsabilidad propia del intelectual en su momento histórico: "lo que afirma Brecht es que la retractación de un hombre de la estatura y la influencia de Galileo no podía menos que asestar un duro golpe a los intereses de la libre investigación y, lo que es más importante, a los intereses de la gente en su totalidad" (Ewen, 2008, p. 299).

Los diversos testimonios de Brecht sobre la obra -y, obviamente, la obra misma- permiten entender la imposibilidad de separar la visión política de la visión estética de Brecht; en términos de Bourdieu, las dos nociones serían disposiciones configuradoras del habitus brechtiano. Vida de Galileo tuvo tres versiones -la primera, en 1938, que, desde el marxismo, parecía estar más orientada a los trabajadores; la segunda, entre 1944 - 1946 y la última, en la que trabajó hasta su muerte (Ewen, 2008, pp. 287-288)-; una de ellas estaba en plena construcción cuando "la 'era atómica' hizo su debut en Hiroshima" (Brecht, 2015, p. 320). Este hecho, para Brecht, significó una lectura diferente de la biografía del fundador de la nueva física:

El infernal efecto de la Gran Bomba situaba el conflicto de Galileo con la autoridad de su tiempo bajo una nueva luz más hiriente. Tuvimos que hacer pocos cambios, ni uno solo en la estructura. Ya en el original la Iglesia estaba representada como la autoridad secular, y su ideología intercambiable con cualquier otra. Desde el principio, el punto clave de la gigantesca figura de Galileo había sido su idea de una ciencia unida al pueblo (Brecht, 2015, p. 320). 
De acuerdo con Frederic Ewen, en sus primeras versiones la obra se concibió de manera tradicional; Galileo se ubicaba como un científico revolucionario y cercano al pueblo, cuya retractación no implicaba mayores perjuicios a su contribución a la humanidad; podía incluso leerse como un gesto sabio que había permitido el avance de las ciencias. Sin embargo, con los problemas urgentes de su tiempo, Brecht cambia radicalmente su posición frente a Galileo y su retractación y surge la pregunta sobre la responsabilidad del intelectual en épocas de crisis y de terror y si la supervivencia plantea un problema de "cobardía moral", asunto que siempre lo inquietó. Bajo esta mirada, la retractación pasó a ser un crimen (Brecht, 2015, p. 319):

GALILEO: $[\ldots]$ La Ciencia, Sarti, tiene que ver con ambas luchas. Una humanidad tambaleante en un vapor nacarado de supersticiones y consejas, demasiado ignorante para desarrollar sus propias fuerzas, no será capaz de desarrollar las fuerzas de la Naturaleza que vosotros le reveláis. ¿Para quién estáis trabajando? Yo sostengo que el único objetivo de la Ciencia es aliviar las fatigas de la existencia humana. Si los científicos, intimidados por los poderosos egoístas, se contentan en acumular Ciencia por la Ciencia misma, se mutilará, y vuestras nuevas máquinas significarán solo nuevos sufrimientos [...] Como científico, tuve una posibilidad excepcional. En mi época, la Astronomía llegó a la plaza pública. En esas condiciones muy especiales, la firmeza de un hombre hubiera podido provocar grandes conmociones. Si yo hubiera resistido, los hombres dedicados a las ciencias naturales hubieran podido desarrollar algo así como el juramento de Hipócrates de los médicos: ¡la promesa de utilizar la Ciencia únicamente en beneficio de la Humanidad! Tal como están las cosas, lo más que se puede esperar es una estirpe de enanos inventores, que podrían alquilarse para todo $[\ldots] \mathrm{Y}$ entregué mi saber a los poderosos para que lo usaran, no lo usaran o abusaran de él, según conviniera mejor a sus fines [...] He traicionado a mi profesión. Un hombre que hace lo que yo he hecho no puede ser tolerado en las filas de la Ciencia (Brecht, 2009, pp. 123-124). 
El asunto del papel del intelectual ha sido el que mayores posibilidades alegóricas ha suscitado en la recepción de la obra, lecturas promovidas incluso por el propio autor: "El viejo cardenal (en la escena 4) es intercambiable, con pocas alteraciones, por un tory o un demócrata del estado de Luisiana" (Brecht, 2015, p. 337). Frederic Jameson señala que la alegoría opera al "retirar el elemento de autosuficiencia del significado de una representación dada" (2013, p. 182). Dentro de estas posibilidades, Jameson asume la retractación de Galileo y su rendición frente al poder de la Iglesia como referente de la aquiescencia de $\mathrm{J}$. Robert Oppenheimer a la fabricación de la bomba o la sumisión de Bujarin ante Stalin $(2013 \text {, p. 182) })^{10}$.

El ejercicio alegórico ha sugerido también que Galileo es la encarnación de Brecht o que, como lo afirma Isaac Deutscher -en lo que Ewen llama conjeturas que no pueden ser probadas (2008, p. 394)-, Galileo era la forma del autor de representar su compleja relación con el poder soviético de los años 30:

Brecht estaba relativamente de acuerdo con el trotskismo y le impactaron las purgas; pero no podía romper con el stalinismo. Lo apoyó con grandes dudas, como lo hicieron aquellos que capitularon en Rusia, y lo expresó a través de la figura de Galileo Galilei. Fue a través del prisma de la experiencia bolchevique que vio a Galileo arrodillándose ante la Inquisición como si se tratara de una "necesidad histórica”, debido a la inmadurez espiritual y política del pueblo. El Galileo de su drama es Zinoviev, Bujarin o Rakovsky con vestuario histórico [ ...] (Deutscher, citado por Ewen, 2008, p. 293).

En su libro dedicado a Brecht, Didi-Huberman (2013) establece una diferencia entre las nociones de toma de partido y toma de posición - esta última, también determinante en los planteamientos de Bourdieu-; mientras la primera alude a la actitud frente a la instancia política dominante, en este caso el totalitarismo, a partir del discurso y del compromiso con el Partido Comunista ${ }^{11}$, la segunda, más profunda si se quiere, revela una conciencia para situarse en el tiempo, para desear, para exigir; tomar posición es situarse en el presente y aspirar a un futuro (Didi-Huberman, 2013, p. 9).

Por la primera, la toma de partido, caracterizada entre otras cosas por su afinidad con el estalinismo, en una relación de mayor heteronomía que autonomía, Brecht recibió duras críticas -que afectaron también a su amigo Walter Ben-

10. Nikolái Bujarin (1888-1938), ideólogo y miembro de la dirección bolchevique durante los años 20, ejecutado durante la Gran Purga del Partido Comunista Soviético.

11. Aclara Didi-Huberman (2013) que esta toma de partido, en Brecht, no fue del todo ingenua, pues alcanzó en un momento a reconocer que se había vuelto un poco doctrinario (p. 105). 
jamin-, entre las que se destacaron las de Theodor Adorno y Hannah Arendt. Sobre los comentarios de esta última, señala Didi-Huberman (2013) que:

Brecht tuvo, en el exilio, el valor de decir: facultad por excelencia del poeta, es decir "alguien que debe decir lo indecible, que debe no quedarse silencioso en circunstancias en que todos lo están, y que de hecho debe tener cuidado para no hablar demasiado de cosas de las que todo el mundo habla”. Pero con su reconocimiento oficial y su Premio Stalin, solo tuvo la facilidad de callar las contradicciones y ya no ofreció, así, más que "un documento ejemplar de la incertidumbre de las relaciones entre la poesía y la política, [entre otras cosas por] la adhesión doctrinaria y a menudo ridícula [que otorgó] a la ideología comunista”. Desde ese momento, por otra parte, su poesía se hizo tan mala, según Arendt, como comprometida estaba (p. 108).

De la toma de posición, de otro lado, se desprenden diversas posibilidades de diálogo que permiten trazar caminos y redes de relaciones entre la formulación teórico-estética brechtiana como andamiaje para una postura práctica e histórica frente a la realidad -por demás, en completa consonancia con la visión práctica que persigue Bourdieu- y el trasfondo filosófico de la actividad de Galileo, de acuerdo con lo mencionado por Russell y reconocido también por Garin (1984). En este sentido, sin pretender desentrañar un código que revele la verdad, un ejercicio fecundo es leer las palabras del arrepentimiento de Galileo (Brecht, 2009, pp. 123-124) en clave de arte, en lugar de hacerlo en clave de ciencia.

Si bien Brecht tuvo algunas reservas frente a Vida de Galileo, por considerarla «oportunista» y porque en cierta medida sentía que se desviaba del teatro épico (Ewen, 2008, p. 298), se encuentra en ella la relación directa entre la obsesión por la observación y la experimentación práctica de su héroe y el método estético brechtiano: científico, histórico y práctico. El teatro épico es la toma de posición en el campo literario frente a dos mil años de hegemonía aristotélica en cuanto al problema psicológico de la identificación emocional.

Para Brecht, desde La Poética hasta el siglo XX, el arte dramático apeló a los sentimientos de los espectadores, dejando de lado la razón y la toma de conciencia, tradición que derivó en efectos de alienación, autonomización y manipulación; en otras palabras, pérdida de autonomía. De hecho, los mismos totalitarismos recurrieron a estas reacciones sentimentales en sus prácticas comunicativas: "El fascismo, con su grotesca acentuación de lo emocional, y, quizá en igual medida, un cierto deterioro del elemento racional en la doctrina del marxismo me condujeron a poner más énfasis en el elemento racional" (Brecht, 2015, p. 21).

Bajo esta visión, la única forma que le queda al espectador para contrarrestar esta especie de dominación es a través de una reflexión libre y crítica que se 
centre en lo terrenal y lo contingente: "renunciar a las pretensiones de una literatura 'para la eternidad' y de asumir, al contrario, una relación más directa con la actualidad histórica y política” (Didi-Huberman, 2013, p. 16). O, en palabras de Roland Barthes (2009), negarle al hombre toda esencia, sostener que no hay un mal eterno sino males remediables y "volver a poner el destino del hombre en manos del propio hombre” (p. 233).

Señala Jameson (2013) que, más que unos contenidos, más que una colección de hechos, convicciones o pensamientos, el verdadero legado de Brecht fue un método capaz de condensar una toma de posición en una teoría dramática (p. 14). Es claro entonces que recursos de la confección del tex to como la discontinuidad cronológica, la alta presencia del componente narrativo en teatro o la total autonomía de las escenas; recursos de la representación como la no identificación o toma de distancia crítica del actor frente a su personaje o la confrontación al espectador por medio de la acción; o recursos de la creación del personaje como la formulación de seres incompletos, contradictorios y mutables configuran, más que una teoría, una forma práctica de acercarse al mundo.

Una producción bien hecha es aquella de la que han sido borrados los rastros de los ensayos (así como se hacen desaparecer las huellas de la producción en todos los bienes y productos exitosamente reificados); pero Brecht rasga esta superficie y nos permite observar los gestos y las posturas alternativas de los actores, mientras estos intentan construir sus personajes: de modo tal que la experimentación estética en general -a la que con tanta frecuencia se le atribuye el rol de generadora de lo nuevo y, por ende, de lo no experimentado: la innovación radical- también podría interpretarse como un intento 'experimental' de prevenir la reificación (algo que las otras artes, desde las novelas y el cine hasta la poesía, la pintura y la performance musical, incluso la performance aleatoria, están estructuralmente menos calificadas para hacer) (Jameson, 2013, p. 27).

Didi-Huberman (2013) resume esta postura en la idea de "mostrar mostrando que se muestra” que es, a fin de cuentas, la forma de distanciamiento de lo conocido para "hacer de la imagen una cuestión de conocimiento y no de ilusión” (p. 61-62). ¿No es acaso esta la misma línea del “desencanto” que plantea Bourdieu al mencionar uno de los posibles efectos de la aplicación de su metodología? Sí, aunque si bien no se trata de encontrar lo brechtiano en Bourdieu -revivir a Brecht hoy podría resultar profundamente anti-brechtiano (Jameson, 2013)-, el abandono de la aproximación al texto literario desde la concepción esencialista produce una des-ilusión, que abre entonces la opción de acercamiento a la obra desde su necesidad histórica, necesidad que, dependiendo de las condiciones -a 
su vez históricas- de la mirada, permitirá entrar en un juego de temporalidades e intereses históricos que, desde una noción práctica y social, amplía las posibilidades de diálogo y las redes de relaciones de la obra.

El concepto de "necesidad histórica” es abordado por Pierre Bourdieu a partir de los trabajos del historiador inglés Michael Baxandall (citado por Bourdieu, 2015), quien, al estudiar el campo artístico del Renacimiento -tanto en la producción como en la recepción-, propone que para reconstruir la «mirada moral y espiritual» de la época deben revisarse los sistemas de percepción, valoración, juicio y goce adquiridos en las prácticas de la vida cotidiana ${ }^{12}$; es decir, el análisis debe remitirse a la restitución de la experiencia social del mundo (Bourdieu, 2015 , p. 465).

En el caso de la recepción de la obra de Brecht, poco tiempo después de su muerte, de acuerdo con Jameson (2013), fueron tres las lecturas históricamente condicionadas, por parte de tres campos diferentes de la estructura social, que podrían entenderse como tres necesidades históricas distintas: la burguesía, necesitada de una estética nueva; la izquierda, necesitada de una teoría política y de una estrategia comunicativa que fuera transferible a nuevos medios y situaciones, y el tercer mundo, necesitado de una figura que les diera voz a nuevas expresiones de los países recientemente descolonizados (Jameson, 2013, p. 36).

\section{Conclusiones}

Al final de la obra, años después de la retractación, Galileo se encuentra recluido en su casa, por orden de la Inquisición. Enfermo y prácticamente ciego, ha continuado con algunos de sus trabajos bajo el estricto control de funcionarios de la Iglesia, que le retiran los documentos a medida que los va terminando. De pronto, llega Andrea Sarti, convertido ya en un hombre maduro. La conversación se inicia de manera tensa. Él ha venido a despedirse, pues ha decidido trasladarse a Holanda. Galileo le confiesa que ha estado escribiendo los Discorsi, una teoría nueva sobre un tema muy viejo: el movimiento, y que, por vanidad, ha guardado una copia. El joven queda gratamente sorprendido; intuye que el viejo sabio tenía todo calculado, que se había retractado para continuar secretamente con sus avances y velar por el desarrollo de la ciencia. Lo invade de nuevo la admiración por su maestro. Pero no fue así: nunca hubo un plan; Galileo, hijo de las circunstancias, se había retractado por temor al dolor físico que lo dominó al ver

12. "(...) en la escuela, en la iglesia, en el mercado, asistiendo a clases, oyendo discursos o sermones, midiendo pilas de trigo o cortes de paño o resolviendo problemas de intereses compuestos o de seguros marítimos" (Bourdieu, 2015, p. 465). 
los instrumentos con los que sería torturado. La motivación de la determinación había sido práctica, contingente, no trascendental.

Si para Pierre Bourdieu, en La educación sentimental, la estructura social del espacio en que vive Frédéric es también la estructura del espacio social en que se sitúa el autor, en Vida de Galileo, con la diferencia evidente de que no se da esa "reproducción" del espacio social para héroe y autor, son evidentes ciertas consonancias que abren posibilidades inagotables de relacionamiento para la comprensión histórica de la obra: una de ellas, la necesidad histórica de acudir a un método que desde la experiencia práctica se aleje de las verdades universales.

Así, de un lado, a partir de la experiencia económica, didáctica, social, académica y política del día a día del héroe y sus personajes, la obra reconstruye la necesidad de atender a ese camino práctico -experimentar, jugar, mirar a través de un telescopio- para quebrar verdades sustentadas por años bajo las fuentes de conocimiento que sostienen el poder. De otro lado, a partir de la postura estética, Brecht formula un teatro soportado en la conciencia social e histórica de los problemas contingentes y terrenales que persigue que los espectadores tomen distancia -y posición- frente a los discursos universalizantes, a través de los cuales los totalitarismos de inicios del siglo XX buscaron imponer su violenta unificación ideológica.

\section{Referencias}

Arendt, H. (2014). Más allá de la filosofía. Escritos sobre cultura, arte y literatura. Madrid, España: Ediciones Trotta.

Barthes, R. (2009). Escritos sobre el teatro. Barcelona, España: Paidós.

Bourdieu, P. (1989). El campo literario. Prerrequisitos críticos y principios de método. Revista Criterios, 25, 20-42. http://educacion.deacmusac.es/practicaslegitimadoras/files/2010/05/bourdieucampo.pdf [Consultado el 10 de diciembre de 2019$]$.

Bourdieu, P. (2015). Las reglas del arte. Génesis y estructura del campo literario. Barcelona, España: Anagrama.

Brecht, B. (2009). Vida de Galileo. Madre Coraje y sus hijos. Madrid, España: Alianza Editorial. 
Brecht, B. (2015). Escritos sobre teatro. Barcelona, España: Alba.

Didi-Huberman, G. (2013). Cuando las imágenes toman posición. Madrid, España: A. Machado Libros.

Deterich, G. (2015). Escritos sobre teatro. Barcelona, España: Albai.

Ewen, F. (2008). Bertolt Brecht. Su vida, su obra, su época. Buenos Aires, Argentina: Adriana Hidalgo editora.

Garin, E. (1984). La revolución cultural del Renacimiento. Barcelona, España: Editorial Crítica.

Jameson, F. (2013). Brecht y el método. Buenos Aires, Argentina: Manantial.

Russell, B. (1975). La perspectiva científica. Barcelona, España: Editorial Ariel.

Suvin, D. (1998). Introducción a Brecht. Madrid, España: Akal Ediciones.

Vasari, G. (1996). Las vidas de los más excelentes pintores, escultores y arquitectos. D. F.: Universidad Autónoma de México. 
